\title{
Functional group analysis of Moringa concanensis Nimmo (Moringaceae) by FTIR spectrum
}

\author{
K. Santhi ${ }^{1}$ and R. Sengottuvel ${ }^{* 1}$

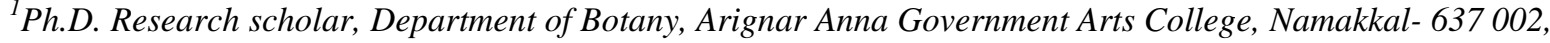 \\ Tamil Nadu, India \\ ${ }^{I}$ Asst. Professor, Department of Botany, Arignar Anna Government Arts College, Namakkal- 637 002, \\ Tamil Nadu, India
}

\begin{abstract}
In the present study deals with the FTIR profile and identify the functional components of methanol extracts of different parts of the (leaf, flower and seed) of Moringa concanensis Nimmo. The FTIR analysis was performed on a Thermo scientific spectrometer SMART iTR basic in NICOLET iS10 model using with ZnSe (zinc selenium) semiconductor the extracted plant samples of $\mathrm{M}$. concanensis were scanned at room temperature within a spectral range of $4000-400 \mathrm{~cm}^{-}$. The vibrational assignments, intensities and dominant peak were obtained from absorption spectra. The results of the present study confirmed the presence of the different types of functional groups like amides, alcohols, amines, alkanes, acids, aldehydes, carboxylic acids, carbonyl, alkynes, alkenes, aromatic compounds, aliphatic amines, esters in the different parts of the plant extract. In future, $M$. concanensis used to different types of ailments and to treat various diseases.
\end{abstract}

Key words :- FTIR Spectrum, Functional groups, Moringa concanensis Nimmo,

\section{INTRODUCTION}

India has recognized more than 2500 plants are of medicinal values. Medicinal plants have been used in traditional for several years. The medicinal plants are of great importance to the different types of human diseases without side effects [1]. Plants have great potential uses especially traditional, pharmacopoeial drugs and various compounds. This is shows that better understanding the plant and their derived properties of compounds. In the current scenario, many plants proved as scientifically their medicinal properties and its significance [2].

The plant M. concanensis (Moringaceae) has a single genus with 13 species have been recorded in India. It is an evergreen tree, widely distributed on dry lands. Commonly known as Kattumurungai or Peyimurungai in Tamil. The entire plant is contains different types of phytoconstituents and they are used nutritional and medicinal benefits. The different parts of the plants are used in different types of ailments and various human diseases such as anti inflammatory, antifertility agent, analgesic, antimicrobial, reduce cholesterol, skin tumor, diabetes, and eye care etc [3-6].

In recent years, the FTIR spectroscopy has played an important role in pharmaceuticals. The FTIR spectrum is mostly used to identify the chemical constituents and elucidate the compound structures and has been used as requisite method to identify medicines in pharmacopoeia of many countries. The spectra of identification of pure compounds are usually so unique that they are like a "molecular fingerprint". An unknown compound can be identified by comparison of known compounds. The FTIR spectrum as a tool for distinguishing closely associated plants and other organisms for applied many researchers.

Identify medicinal materials from the adulterate and even evaluate the quality of the medicinal materials. Amines and amides are the main group of protein synthesis. Carboxylic acids are biologically important in the formation of fat in the body and act as strong antibacterial agents. They serve as main pharmaceutical products in curing some human diseases. Esters in combination with volatile oils produce the pleasant aroma of fruit. Alkynes have been isolated from a wide variety of plant species fungi, corals and marine sponges. Some pharmaceuticals are also alkynes such as contraceptive norethynodrel. Some acids contain alkynes. They possess antifungal, antitumor and antiviral properties. Alkanes are found in the plant cuticle and epicuticular wax of many species. They protect the plant against water loss, prevent the leaching of important minerals by rain and protect against microorganisms and harmful insects. Alkenes are important in the manufacture of plastics E.g. Polythene as a fuel and illuminant. Aldehydes are used in the production of resins when combined with phenols [7]. The aim of the present study was to identify the functional groups present in M. concanensis by FTIR method. 


\section{MATERIALS AND METHODS}

\subsection{Selection of plant species}

The plant materials (leaf, flower and seeds) of M. concanensis Nimmo were collected from the Kunnam of Perambalur district, Tamil Nadu. The different parts of the plant were washed thoroughly 2-3 times with running tap water and once sterile with distilled water. Then the plant parts were shade dried and coarsely powdered separately and stored in air tight glass bottles for further analysis in laboratory.

\subsection{Authentication of plant materials}

The plant was authenticated at Botanical Survey of India [BSI], Southern Circle, Coimbatore. India. The voucher number is (BSI/SRC/5/23/2015/Tech/2185).

\subsection{Preparation of extract}

Fresh plants were dried at room temperature for two weeks following which they were powdered with a hand mill [8]. About one $\mathrm{g}$ of the powdered material was then subjected to extractions using Soxhlet apparatus in AR grade methanol for a duration extending up to 6 hours [9]. The extracts were finally filtered and subsequently concentrated in rotary evaporator under reduced pressure (vacuum $175 \mathrm{mbar}$ for bp at $40{ }^{\circ} \mathrm{C}$ ) to result in thick green crude extracts [10].

\subsection{Spectroscopic analysis by FT-IR}

The FTIR spectra, generated by a sophisticated, OMNIC software computer controlled FTIR, were recorded in Thermo scientific spectrometer SMART iTR basic in NICOLET iS10 model. Using with ZnSe (zinc selenium) semiconductor the extracted plant samples of $M$. concanensis were scanned at room temperature within a spectral range of $4000-400 \mathrm{~cm}^{-}{ }^{-1}$. In the present work it is possible to directly relate the intensities of absorption bands to the concentration of the corresponding functional groups.

\section{RESULTS AND DISCUSSION}

The absorption spectra of leaf sample in (fig.1 and table-1).The band at $3396.46 \mathrm{~cm}^{-1}$ assigned for N-H stretch in amides, alcohols and amines. The band at $2987.43 \mathrm{~cm}^{-1}$ and $2946.27 \mathrm{~cm}^{-1}$ assigned for C-H stretch in alkanes and acids. The band at $2912.38 \mathrm{~cm}^{-1}$ for C-H stretch in alkanes. The band at $2834.49 \mathrm{~cm}^{-1}$ indicates $\mathrm{C}-\mathrm{H}$ stretch of aldehydes and acids. The peak at $2524.07 \mathrm{~cm}^{-1}$ assigned for $\mathrm{O}-\mathrm{H}$ stretch in carboxylic acids. $\mathrm{C} \equiv \mathrm{C}$ stretching was found to be alkynes present due to the appearance of absorption peak at $2226.40 \mathrm{~cm}^{-1}$. The peak at $1659.54 \mathrm{~cm}^{-1}$ shows amides and alkenes indicates $\mathrm{C}=\mathrm{C}$ stretching. The band at $1477.37 \mathrm{~cm}^{-1}$ and $1449.14 \mathrm{~cm}^{-1}$ assigned C-C stretch in aromatic compounds. The peak at $1197.87 \mathrm{~cm}^{-1}$ and $1028.57 \mathrm{~cm}^{-1}$ was due to the C-O stretch of alcohols and amines. The peak at $1104.09 \mathrm{~cm}^{-1}$ shows alcohols and amines indicated C-O stretching.

The absorption spectra of flower sample are shown in (fig. 2 and table-2). The band at $3418.94 \mathrm{~cm}^{-1}$ assigned for N-H stretching in amines. The peak at $2988.39 \mathrm{~cm}^{-1}, 2946.39 \mathrm{~cm}^{-1}$ and $2909.41 \mathrm{~cm}^{-1}$ assigned for C$\mathrm{H}$ stretching of alkanes. C-H stretching was found to be aldehydes and acids presence due to the appearance of absorption peak at $2835.21 \mathrm{~cm}^{-1}$. O-H stretching indicates carboxylic acid the band at $2224.61 \mathrm{~cm}^{-1}$ representing alkynes indicates $\mathrm{C} \equiv \mathrm{C}$ stretching. The band at $1667.22 \mathrm{~cm}^{-1}$ assigned for $\mathrm{C}=\mathrm{O}$ stretching in carbonyl and amides. The peak at $1478.91 \mathrm{~cm}^{-1}$ and1449.50 $\mathrm{cm}^{-1}$ indicates C-C stretching of aromatics. The peak at $1197.92 \mathrm{~cm}^{-1}$ represents alkynes and esters indicated $\mathrm{C}-\mathrm{O}$ stretching. C-O stretching was found to be $1103.98 \mathrm{~cm}^{-1}$ represent alcohols, amines and esters. The band at $1028.00 \mathrm{~cm}^{-1}$ assigned for $\mathrm{C}-\mathrm{O}$ stretch in alcohols and esters. The band at $684.08 \mathrm{~cm}^{-1}$ indicated $\mathrm{C}-\mathrm{H}$ bend shows alkanes.

The absorption spectra of seed sample show in (fig.3 and table-3). The peak at $3406.44 \mathrm{~cm}^{-1}$ representing amines, alcohols and amides indicated N-H stretching. The band at $2988.45 \mathrm{~cm}^{-1}$ and $2946.19 \mathrm{~cm}^{-1}$ assigned for C-H stretching in alkanes. C-H stretching was found to be $2834.82 \mathrm{~cm}^{-1}$ represent in aldehydes and acids. The band at assigned for $\mathrm{O}-\mathrm{H}$ stretch in carboxylic acid. The peak at $1666.88 \mathrm{~cm}^{-1}$ present in $\mathrm{C}=\mathrm{C}$ stretching presence of amides and alkenes. The peak at $1589.22 \mathrm{~cm}^{-1}$ representing in C-C stretching of aromatics and amides. C-C stretching was found to be $1478.64 \mathrm{~cm}^{-1}$ and $1450.30 \mathrm{~cm}^{-1}$ indicated aromatics. The band at $1179.35 \mathrm{~cm}^{-1}$ assigned for C-O stretch in alkynes and esters. The band at $1103.56 \mathrm{~cm}^{-1}$ shows alcohols, amines and esters Presence of C-O stretching. The peak at $1028.71 \mathrm{~cm}^{-1}$ representing aliphatic amines indicates C-N stretching. The FTIR studies have been carried out by different workers with the report of different types of functional groups such as amines, alkanes, esters, aromatic, alcohols, carboxylic acids etc [11-21]. 


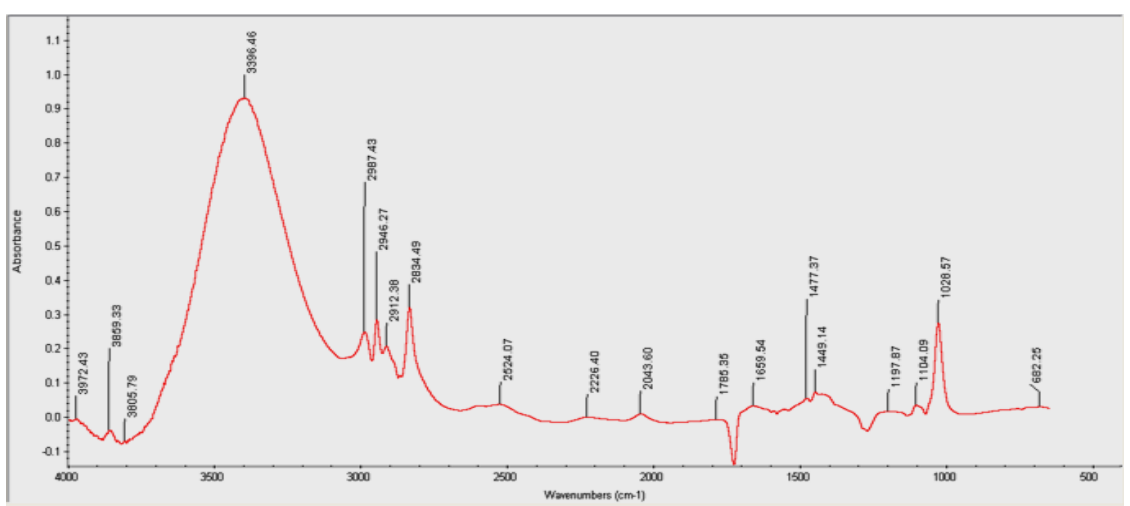

Fig. 1: FTIR spectrum of leaf methanolic extract of $M$. concanensis

Table -1

FTIR spectrum peak values, intensities and functional groups of leaf methanolic extract of M. concanensis

\begin{tabular}{|l|l|l|l|l|l|}
\hline S.no & Peak values & $\begin{array}{l}\text { Intensity } \\
\text { range }\end{array}$ & Intensity & $\begin{array}{l}\text { Group } \\
\text { assignment }\end{array}$ & Functional group \\
\hline 1 & 3972.43 & 0.0086 & & & Unknown \\
\hline 2 & 3859.33 & 0.0412 & & & Unknown \\
\hline 3 & 3805.79 & 0.0733 & & Unknown and \\
\hline 4 & 3396.46 & 0.9280 & Medium & N-H stretch & $\begin{array}{l}\text { Amides, alcohols and } \\
\text { amines }\end{array}$ \\
\hline 5 & 2987.43 & 0.2450 & Medium & C-H stretch & Alkanes and acids \\
\hline 6 & 2946.27 & 0.2810 & Medium & C-H stretch & Alkanes and acids \\
\hline 7 & 2912.38 & 0.2040 & Medium & C-H stretch & Alkanes \\
\hline 8 & 2834.49 & 0.3170 & Weak & C-H stretch & Aldehydes and acids \\
\hline 9 & 2524.07 & 0.0337 & Medium & O-H stretch & Carboxylic acids \\
\hline 10 & 2226.40 & 0.0033 & Weak & $\begin{array}{l}\text { C } \text {-C } \\
\text { stretch }\end{array}$ & Alkynes \\
\hline 11 & 2043.60 & 0.0059 & & & Unknown \\
\hline 12 & 1785.35 & 0.0104 & & Unknown \\
\hline 13 & 1659.54 & 0.0303 & Medium & $\begin{array}{l}\text { C=C } \\
\text { stretch }\end{array}$ & Amides and alkenes \\
\hline 14 & 1477.37 & 0.0519 & Medium & C-C stretch & Aromatic compounds \\
\hline 15 & 1449.14 & 0.0692 & Medium & C-C stretch & Aromatic compounds \\
\hline 16 & 1197.87 & 0.0130 & Strong & C-O stretch & Alcohols \\
\hline 17 & 1104.09 & 0.0314 & Strong & C-O stretch & Alcohols and amines \\
\hline 18 & 1028.57 & 0.2720 & Strong & C-O stretch & Alcohols \\
\hline 19 & 682.25 & 0.0261 & Strong & C-H bend & Alkenes \\
\hline
\end{tabular}

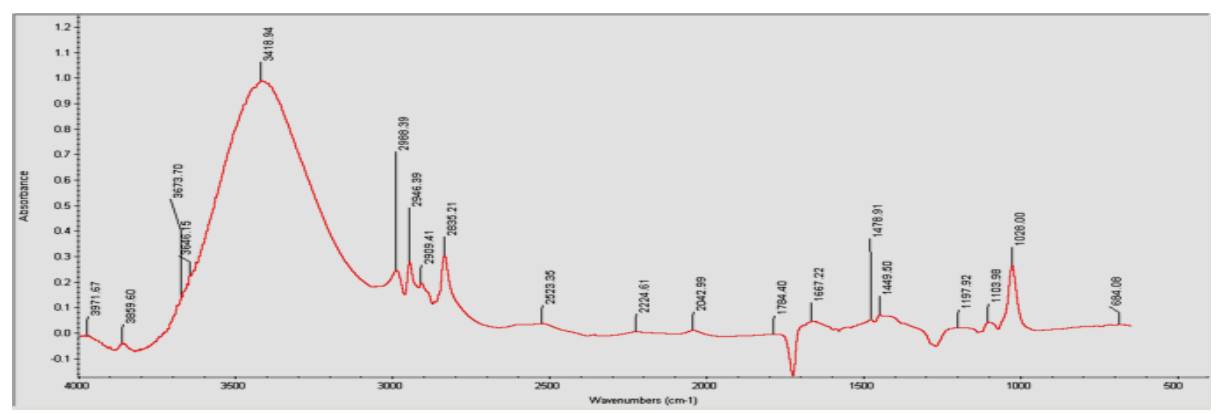

Fig.2: FTIR spectrum of flowers methanolic extract of $M$. concanensis 
Table -2

FTIR spectrum peak values, intensities and functional groups of flower methanolic extract of M. concanensis

\begin{tabular}{|l|l|l|l|l|l|}
\hline S.no & $\begin{array}{l}\text { Peak } \\
\text { values }\end{array}$ & $\begin{array}{l}\text { Intensity } \\
\text { range }\end{array}$ & Intensity & $\begin{array}{l}\text { Group } \\
\text { assignment }\end{array}$ & Functional group \\
\hline 1 & 3971.67 & 0.0129 & & & Unknown \\
\hline 2 & 3859.60 & 0.0425 & & & Unknown \\
\hline 3 & 3673.70 & 0.1460 & & & Unknown \\
\hline 4 & 3646.15 & 0.2270 & & & Unknown \\
\hline 5 & 3418.94 & 0.9870 & Medium & N-H stretch & Amines \\
\hline 6 & 2988.39 & 0.2420 & Medium & C-H stretch & Alkanes \\
\hline 7 & 2946.39 & 0.2750 & Medium & C-H stretch & Alkanes \\
\hline 8 & 2909.41 & 0.1930 & Medium & C-H stretch & Alkanes \\
\hline 9 & 2835.21 & 0.3020 & Weak & C-H stretch & Aldehydes and acids \\
\hline 10 & 2523.35 & 0.0333 & Medium & O-H stretch & Carboxylic acid \\
\hline 11 & 2224.61 & 0.00024 & Weak & C $\equiv$ C stretch & Alkynes \\
\hline 12 & 2042.99 & 0.0063 & & & Unknown \\
\hline 13 & 1784.40 & 0.0085 & & & Unknown \\
\hline 14 & 1667.22 & 0.0422 & Strong & C=O stretch & Carbonyl and amides \\
\hline 15 & 1478.91 & 0.0486 & Medium & C-C stretch & Aromatic \\
\hline 16 & 1449.50 & 0.0679 & Medium & C-C stretch & Aromatic \\
\hline 17 & 1197.92 & 0.0166 & Strong & C-O stretch & Alkynes and esters \\
\hline 18 & 1103.98 & 0.0389 & Strong & C-O stretch & Alcohols, amines and esters \\
\hline 19 & 1028.00 & 0.2610 & Strong & C-O stretch & Alcohols and esters \\
\hline 20 & 684.08 & 0.0285 & Strong & C-H bend & Alkenes \\
\hline
\end{tabular}

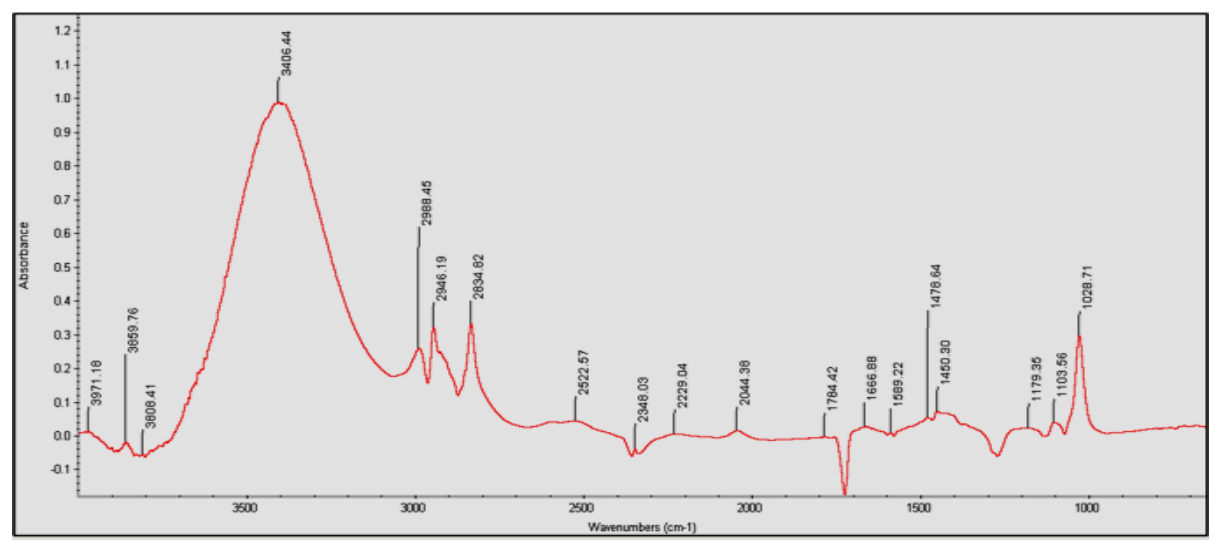

Fig. 3: FTIR spectrum of seed methanolic extract of $M$. concanensis

Table -3

FTIR spectrum peak values, intensities and functional groups of seed methanolic extract of M. concanensis

\begin{tabular}{|l|l|l|l|l|l|}
\hline S.no & $\begin{array}{l}\text { Peak } \\
\text { values }\end{array}$ & $\begin{array}{l}\text { Intensity } \\
\text { range }\end{array}$ & Intensity & $\begin{array}{l}\text { Group } \\
\text { assignment }\end{array}$ & Functional group \\
\hline 1 & 3971.18 & 0.0109 & & & Unknown \\
\hline 2 & 3859.76 & 0.0224 & & & Unknown \\
\hline 3 & 3808.41 & 0.0589 & & & Unknown \\
\hline
\end{tabular}




\begin{tabular}{|l|l|l|l|l|l|}
\hline 4 & 3406.44 & 0.986 & $\begin{array}{l}\text { Strong, } \\
\text { Broad }\end{array}$ & N-H stretch & $\begin{array}{l}\text { Amines, alcohols and } \\
\text { amides }\end{array}$ \\
\hline 5 & 2988.45 & 0.256 & Medium & C-H stretch & Alkanes \\
\hline 6 & 2946.19 & 0.319 & Medium & C-H stretch & Alkanes \\
\hline 7 & 2834.82 & 0.327 & Weak & C-H stretch & Aldehydes and acids \\
\hline 8 & 2522.57 & 0.0400 & Medium & O-H stretch & Carboxylic acid \\
\hline 9 & 2348.03 & 0.0417 & & & Unknown \\
\hline 10 & 2229.04 & 0.0012 & & & Unknown \\
\hline 11 & 2044.38 & 0.0107 & & & Unknown \\
\hline 12 & 1784.42 & 0.0083 & & & Unknown \\
\hline 13 & 1666.88 & 0.0230 & Medium & C=C stretch & Amides and alkenes \\
\hline 14 & 1589.22 & 0.0045 & Medium & C-C stretch & Aromatic and amides \\
\hline 15 & 1478.64 & 0.0508 & Medium & C-C stretch & Aromatic \\
\hline 16 & 1450.30 & 0.0690 & Medium & C-C stretch & Aromatic \\
\hline 17 & 1179.35 & 0.0185 & Strong & C-O stretch & Alkynes and esters \\
\hline 18 & 1103.56 & 0.0353 & Strong & C-O stretch & $\begin{array}{l}\text { Alcohols, amines and } \\
\text { esters }\end{array}$ \\
\hline 19 & 1028.71 & 0.292 & Medium & C-N stretch & Aliphatic amines \\
\hline
\end{tabular}

\section{CONCLUSION}

The results of the present study was concluded that traditional use of $M$. concanensis Nimmo for the human ailments and its partly explained its use in herbal medicine. Thus this plant can be utilized as an alternative source of useful drugs. The presence of different characteristic functional groups are identified, these are responsible for different kind of biological activities depending their pharmaceutical and therapeutic uses. Further studies are needed with this plant to dissociate, characterize and illustrate the compounds.

\section{ACKNOWLEDGEMENT}

I am kindly expressing sincere thanks to my respected guide Asst. Prof Dr. R. Sengottuvel for their valuable time and suggestions given to me.

\section{REFERENCES}

[1] P. Ragavendran, D. Sophia, C. Arul Raj and V.K Gopikrishnan, Functional group analysis of various extracts of Aerva lantata (L.,) by FTIR spectrum, Pharmacology online Newsletter, 1, 2011, 358-364.

[2] T. Antony Sandosh, M. Paul John Peter and J. Yesu Raj, Phytochemical analysis of Stylosanthes fruticosa using UV-VIS, FTIR and GC-MS, Research Journal of Chemical Sciences, 3(11), 2013, 14- 23.

[3] K. Santhi and R. Sengottuvel. Qualitative and quantitative phytochemical analysis of Moringa concanensis Nimmo, International Journal of Current Microbiology and Applied Sciences, 5(1), 2016, 633-640.

[4] K. Santhi and R. Sengottuvel, Antibacterial activity of methanolic extracts of Moringa concanensis Nimmo, International Journal Pharma and Bio Sciences, 7(3), 2016, 61-65.

[5] V. Balamurugan and V. Balakrishnan, Evaluation of phytochemical, phamacognostical and antimicrobial activity from the bark of Moringa concanensis Nimmo, International Journal of Current Microbiology and Applied Sciences, 2(4), 2013, 117-125.

[6] S. Vijayakumar and A. Sumathi, Preliminary phytochemical and GC-MS analysis of bioactive compounds from Moringa concanensis Nimmo leaves family: Moringaceae. International Journal of Recent Advances in Multidisciplionary Research, 3(2), 2016, 1257-1259.

[7] S. Lakshmi and R. Nair, Functional group analysis of Cleome viscosa L. and C. burmanni W. \& A. (Cleomaceae) extracts by FTIR, Journal of Phamacognosy and Phytochemistry, 2(6), 2014, 120-124.

[8] J. B. Harbourne, Phytochemical Methods, A Guide to Modern Techniques of Plant Analysis, Chapman and Hall London, 1984.

[9] R. Chandrasekar and S. N. Rao, Phytochemical analysis of ethanolic extract of leaves of Leucas indica (EELLI), International Journal of Pharma and Bio sciences, 4(1), 2013, 33-38.

[10] Prashant Tiwari, Phytochemical screening and extraction review, International Journal of Pharmaceutical Sciences, 2011, 1.

[11] Mitra Khani Baseri and S. Baker, Identification of cellular components of medicinal plants using FTIR, Romanian Journal of Biophysics, BUCHAREST, 21, 2011, 277-284. 
[12] B. Renuka, B. Sanjeev and D. Ranganathan, Evaluation of phytoconstituents of Caralluma nilagiriana by FTIR and UV-VIS spectroscopic analysis, Journal of Pharmacognosy and Phytochemistry, 5(2), 2016, 105-108.

[13] T. Starlin, C. Arul Raj , P. Ragavendran and V.K Gopalakrishnan, Phytochemical screening, Functional groups and element analysis of Tylophora pauciflora Wight and arn, International Research Journal of Pharmacy, 3(6), 2013, 180-183.

[14] N. Janakiraman, S. Sahaya Sathish and M. Johnson, UV-VIS and FTIR spectroscopic studies on Peristrophe bicalyculata (Retz.) Nees, Asian Journal of Pharmaceutical and Clinical Research, 4(4), 2011, 125-129.

[15] M. Thenmozhi , P.K Bhavya and S. Rajeshwari, Compounds identification using HPLC and FTIR in Eclipta alba and Emilia sonchifolia, International Journal of Engineering Science and Technology, 3(1), 2011, 292-298.

[16] J. Nithyadevi and R. Sivakumar, Phytochemical Screening and GC-MS, FT- IR analysis of methanolic extract leaves of Solanum torvum Sw. International Journal of Research Studies in Biosciences, 3(9), 2015, 61-66.

[17] Bizuneh Adinew, GC-MS and FT-IR analysis of constituents of essential oil from Cinnamon bark growing in south-west of Ethiopia, International Journal of Herbal Medicine, 1(6), 2014, 22-31.

[18] R. Ashokkumar and M. Ramaswamy, Phytochemical screening by FTIR spectroscopic analysis of leaf extracts of selected Indian medicinal plants, International Journal of Current Microbiology and Applied Sciences, 3(1), 2014, 395-406.

[19] T. Anand and K.Gokulakrishnan, Phytochemical analysis of Hybanthus enneaspermus using UV, FTIR and GC-MS, IOSR Journal of Pharmacy, 2(3), 2012, 520-524.

[20] N. Durga Maha Lakshmi, B. Mahitha T. Madhavi and N. John Sushma, Phytochemical screening and ftir analysis of Clitoria ternatea leaves, International Journal of Scientific \& Engineering Research, 6(2), 2015, 287-290.

[21] M. Ibrahim and M. Abd-El-Aal, spectroscopic study of heavy metals interaction with organic acid, International Journal of Environment and Pollution, 35(1), 2008, 99-110. 